\title{
Agrochemical plastic packaging waste decontamination for recycling: Pilot tests in Italy
}

\author{
Caterina Picuno, ${ }^{1}$ Zoe Godosi, ${ }^{2}$ Kerstin Kuchta, ${ }^{1}$ Pietro Picuno ${ }^{3}$ \\ ${ }^{1}$ Hamburg University of Technology, Institute of Environmental Technology and Energy Economics, Hamburg, \\ Germany; ${ }^{2}$ Civil Engineer, Freelance Consultant, Cellamare (BA), Italy; ${ }^{3}$ SAFE School, University of Basilicata, \\ Potenza, Italy
}

\begin{abstract}
Agriculture, one of the main economic pillars in Europe, plays a growing important role towards the environmental sustainability of the extra-urban land, in which the agricultural activities may proactively contribute to control and regulate the whole ecological conditions. Modern agriculture currently needs big quantities of agrochemicals, which are necessary for the growth and protection of crops and animals. These agrochemicals are commercially distributed to consumers in many types of containers. The most widely used packaging solutions usually employ plastic materials (e.g., containers for liquid pesticide; sacks for granular fertiliser; etc.). These materials, after the use of the agrochemical, need to be decontaminated, before being entrained in a recycling process, in the framework of a circular economy. In the present paper the main results coming from a EU-funded international project are reported, with specific reference to a pilot station that was realised in Italy with the aim to implement and test a codified system for the decontamination of these plastic containers for agrochemicals. The experimental tests were supported by relevant laboratory analysis, which have confirmed that the triple-rinsing decontamination procedure - traditionally employed by farmers for washing
\end{abstract}

Correspondence: Caterina Picuno, Hamburg University of Technology, Institute of Environmental Technology and Energy Economics, Harburger Schloßstraße, 36, D-21079 Hamburg, Germany.

E-mail: caterina.picuno@tuhh.de

Key words: Plastic containers; circular economy; material recycling; waste decontamination.

Contributions: the authors contributed equally.

Conference presentation: this paper has been presented at the Sixth International Conference on: Industrial \& Hazardous Waste Management - CRETE 2018, Chania-Crete (Greece); 4-7 September 2018.

Received for publication: 19 March 2019.

Accepted for publication: 8 May 2019.

(C) Copyright C. Picuno et al., 2019

Licensee PAGEPress, Italy

Journal of Agricultural Engineering 2019; L:958

doi:10.4081/jae.2019.958

This article is distributed under the terms of the Creative Commons Attribution Noncommercial License (by-nc 4.0) which permits any noncommercial use, distribution, and reproduction in any medium, provided the original author(s) and source are credited. and decontaminating these containers - may be effective only under some well-defined conditions. Triple rinsing by farmers has indeed led to an only partial decontamination of the plastic containers, if farmers did not follow an appropriate triple-rinsing protocol, or did not triple-rinse the containers immediately after their emptying.

\section{Introduction}

Agriculture is one of the main economic pillars in Europe, mostly in its southern area which, lying close to the Mediterranean Sea, may benefit from better local weather conditions and more sunny days. Here, agriculture plays indeed a traditional role, which has contributed to a legacy rooted into the history of the whole European continent. Agriculture also plays a growing important role on the current quality of life of European citizens and their dietary habits, as well as towards the environmental sustainability of the extra-urban land, since it safeguards the rural landscape, proactively contributing to regulate and control its whole ecological framework. In the early sixties, to increase the agricultural productivity worldwide, new varieties of plants, called hybrid were introduced. These were more receptive to the nutrients, faster maturation and able to grow in every season, allowing an increase in crop production throughout the year. At the same time, an increase in the use of heavy machinery, wide and extensive diffusion of plastic materials, and massive use of agrochemicals made their entrance in agriculture.

The agricultural plastics are garnering greater attention in recent years because these materials have become ubiquitous in all sectors of agriculture. Plastics are substituted for the longer lasting materials previously used - e.g., concrete, glass, ceramic, metal, etc. - because they are often less costly, safer to use, and improve production efficiency (Picuno, 2014). Modern agriculture currently needs also big quantities of agrochemicals, which are necessary for the growth and protection of crops and animals. The term agrochemicals usually covers a broad range of pesticides, including insecticides, herbicides, and fungicides. However, it may also comprise synthetic fertilisers, hormones and other chemical growth agents, and concentrated stores of raw animal manure. Pesticides not only may harm living target organisms, but they often remain as residues in food, soil, groundwater and air, affecting the agro-ecosystem, as well as the human health. As a matter of fact, pesticides were recently recognised as one of the six world's worst pollution problems affecting human health. Even though gaps in the current data on the issue make it difficult to be precise about the scale and trends of the problem in Europe (Lanorte et al., 2017), there is evidence that the pesticide issue is serious and growing. According to Eurostat, the total quantity of pesticides sold, expressed in active ingredient (a.i.) reported for 
2015 for n. 25 countries, was approximately 385,000 tons. Spain, France, Italy and Germany are the major consumers, using nearly $60 \%$ of the total of plant protection products in EU (Briassoulis et al., 2014; Marsanidis et al., 2018).

The packaging solutions for commercially distributing agrochemicals to consumers usually employ many types of plastic containers - e.g.: containers for liquid pesticide; sacks for granular fertiliser; etc. - composed by a polymer or copolymer or coated polymer. This plastic material, after the use of the agrochemical, needs to be decontaminated, before being entrained into a material recycling process (Briassoulis et al., 2012).

The implementation of the circular economy's principles is leading governments, enterprises, and individuals to embrace practices that favour the reuse of materials. In case of plastic material, the preseparation of polymeric material on the basis of its composition, followed by cleaning and conditioning, may enable a large amount of these materials to be returned to the production system. Traditionally, farmers have often dumped plastic waste recklessly into the environment, burned them, or buried them (ScarasciaMugnozza et al., 2008; Vox et al., 2016). Such practices directly contribute to environmental contamination and pose a public health risk (Briassoulis et al., 2010). After some decades of increasing use, the problem of disposal is ever more difficult to ignore. Several studies indicate that most agricultural plastics which are burned or buried on-farm, create fire hazards, clogging water channels, and releasing high levels of polluting emissions. Agricultural plastics are dispersed across the rural landscape, bulky and often contaminated with debris (e.g., dirt, pebbles, vegetation, chemical residues, moisture), limiting their suitability and value for re-processing (Briassoulis et al., 2013; Blanco et al., 2018).

The mismanagement of agricultural plastic packaging waste (APPW) constitutes a major environmental problem, resulting in pollution of soil, air and water resources and compromising the agricultural products safety, the protection of the environment and public health. Mismanagement of the APPW is reported in many countries of the world. Due to lack of education and guidance in the proper management of small quantities of pesticide-related waste, hazardous chemicals are often left lying around in rural and urban areas, whereas the reuse of contaminated empty containers for domestic purposes, which is frequently identified in many developing areas, is another major health risk (Damalas et al., 2008; Ben Salem et al., 2019). Some schemes for the management of APPW have been established in a few European countries, as in Germany, France and Spain. However, these schemes are incompatible with each other, while in most cases they are not combined in a synergistic way with the management of other agricultural plastic waste (APW) categories to optimise the use of resources, increase efficiency and reduce costs. Thus, for example, the French system Adivalor considers and handles the triple-rinsed containers of agrochemicals as non-hazardous waste, while the Spanish system Sigfito considers them as hazardous waste and handles them in an analogous way. The French system Adivalor also collects agricultural plastic films. In many other European countries, mostly those characterised by an intensive agricultural production (Italy included), no schemes exist for the management of APPW, with serious negative consequences for the environment and public health (Briassoulis et al., 2014).

A systematic approach aimed at proposing a suitable solution for the collection and disposal of APW was at first set by an EUfunded Project (Labelagriwaste project, 2009). Labelagriwaste aimed at designing and implementing a holistic and environmentally sound waste management scheme at pilot scale. The main objective was to minimise the costs and maximise the revenues by transforming the agricultural plastic waste streams into labelled guaranteed quality commodities freely traded in an open market. The labelling management scheme proposed was designed to be technically feasible, economic and able to satisfy the geographic diversity and the various technical requirements of the major stakeholders throughout Europe, including farmers, plastics producers and recyclers, as well as industrial facilities utilising alternative fuels for energy production. In the framework of this project, some experimental investigations were performed about the possibilities of producing through mechanical recycling of postconsumer agricultural plastic film, new plastic film (Picuno et al., 2012) or rigid profiles produced by mixing plastic film with some additives, e.g., glass fibres (Dimitrijevic et al., 2013).

The aim of the present study is to report the main outcomes of the internationally-funded European Project AgroChePack. The main objective is to describe the decontamination procedure performed at pilot scale in Italy, assessing its efficacy from a legal point of view and material recyclability perspective, determining whether storing APPW could hinder its decontamination and therefore the material's circularity.

\section{Materials and methods}

\section{The AgroChePack project}

The European project Design of a Common Agrochemical Plastic Packaging Waste Management Scheme to Protect Natural Resources in Synergy with Agricultural Plastic Waste Valorisation - AgroChePack (AgroChePack Project, 2013), funded by the European Territorial Cooperation MED Programme, was implemented in response to the serious issues arisen as outcomes of the Labelagriwaste project, regarding APPW mismanagement. The AgroChePack project had the aim of developing an integrated, efficient, environmentally friendly and economically viable management system for the management of APPW in Europe. This new system was designed in order to transfer know-how from existing management schemes and with the objective of promoting synergy with other similar schemes previously proposed for the management of other non-hazardous agricultural plastic waste (e.g., plastic film for greenhouse, tunnel, mulching; pipe/tapes for irrigation; etc.). This new integrated APPW management scheme was piloted in five EU countries (Greece, Italy, Cyprus, Spain, and France). In Italy where, as in some other Countries, an APPW management scheme is not yet established, it is necessary to develop appropriate environmentally friendly solutions. The Law Decree n. 22 dated 1997, so-called, Ronchi Decree (D. Lgs. N.22/1997), has implemented the UE Directives - 91/156, 91/689 and $94 / 62$ - in environmental matters which have aligned the Italian legislation with EU requirements. Article 48 of this Law Decree identified polyethylene (not only agricultural) as one of the particular categories of waste requiring specific management procedures. The question of polyethylene waste management required the creation of a compulsory Consortium (PolieCo) with the primary objective of promoting the collection, re-use, and recycling of polyethylene (Labelagriwaste project, 2009).

In accordance with the Italian Law in force (D. Lgs n.152/2006), agrochemical packaging (with residues after their use, or still full with an expired product) are currently classified as a hazardous waste; they are described by CER code 150110 unwashed empty containers for plant protection or agrochemical products. This law includes in the list of special non-hazardous 
waste also the agrochemical packaging after decontamination, but without specifying any standardised procedure to decontaminate them. In order to address this legal gap and meet the needs of the farmers in different Italian provinces, special Programme Agreements between Local Authorities (Municipalities and/or Provinces) and the relevant stakeholders have in some cases standardised the decontamination procedures, following relevant protocols established with the international experience. Specific guidelines are offered on the understanding that where local laws and regulations are already in place, these must take priority. These guidelines can and should, however, be used in dialogue with the relevant authorities, to help shaping new laws and regulations, while revising the existing ones.

The pilot tests in Italy of the AgroChePack Project were performed in the Apulia Region, a southern region in which agriculture plays a pivotal role in its socio-economic development, as well as in its environmental sustainability. A preliminary analysis, mapping APPW generation was performed, by collecting information on cultivations (main species, cultivated areas and their localisations), plastic material and agrochemical products used to estimate APPW streams (quantity, temporal and spatial distribution, problems experienced with specific disposal solutions applied, etc.) and on farmers' awareness about the environmental damage caused by a poor waste management (Sica et al., 2013). This analysis was taken as a basis for the realisation of the pilot plant (Figure 1).

In this pilot plant, specific pilot tests were performed, aimed to critically assess the possibility to implement the European Crop Protection Association's (ECPA) policy on container management strategies, consisting essentially in three different rinsing options: i) triple-rinsing, according to the specific procedure developed under the AgroChePack project (Figure 2); ii) pressure rinsing (Figure 3); iii) integrated rinsing.

Basing on the results obtained in this pilot station, successive experimental tests in view of recyclability of the polymeric material were conducted in the laboratory of the Institute of Environmental Technology and Energy Economics of the Hamburg University of Technology (Hamburg, Germany). A general evaluation of the recyclability of the APPW material was performed by assessing the degradation of the polymer containing the pesticide, regardless of the current storage practices of the farmers. A known level of degradation was introduced in the polymer through heat-treatment and photo-oxidation, in order to investigate if and to what extent the changes in the material, occurring due to degradation, hinder the decontamination procedure.

This method of accelerated ageing could simulate long storage time options (i.e. long storage time of the container without immediate decontamination, long storage time of a container with the pesticide not fully used and stored for a future application). More specifically, the simulated storage time was calculated using Equation (1) (Alassali et al., 2018):

$t_{(\text {storage })}=t_{\text {real }} \times Q_{10}\left(T_{\text {aging }}-T_{\text {ambient }}\right)^{/ 10}$

where:

$t_{\text {storage: }}$ storage time in days;

$t_{\text {real }}$ : the real aging time applied, using accelerated conditions in days;

$Q_{10}$ : accelerated aging factor. Based on the material, a value of 2 is considered (Alassali et al., 2018);

$T_{\text {aging: }}$ the aging temperature applied $\left({ }^{\circ} \mathrm{C}\right)$;

$T_{\text {ambient: }}$ the ambient temperature $\left({ }^{\circ} \mathrm{C}\right)$.

\section{Samples preparation and decontamination procedure}

Two identical PE/PA pesticide bottles with a $0.75 \mathrm{~L}$ volume were subject to decontamination according to the triple-rinsing procedure (Figure 2) described in the Guidelines for small containers outlined as a result of the AgroChePack Project. The bottles

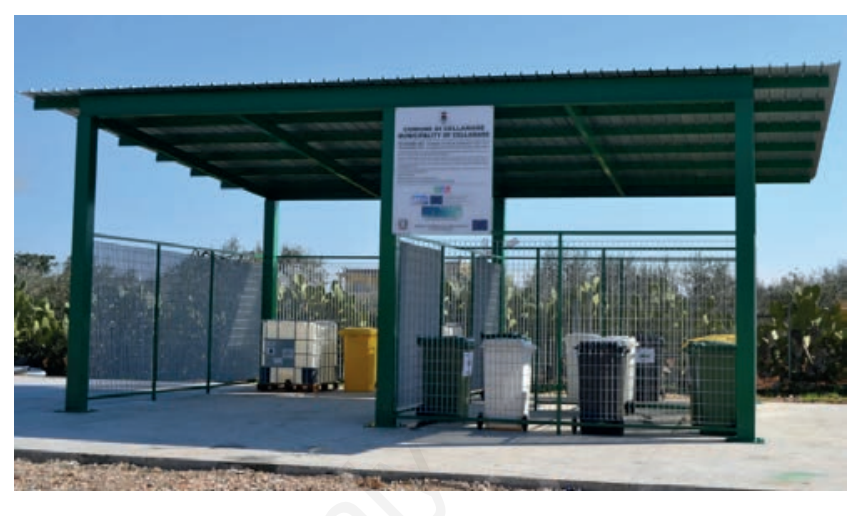

Figure 1. The AgroChePack pilot station at Cellamare (BA, Italy).

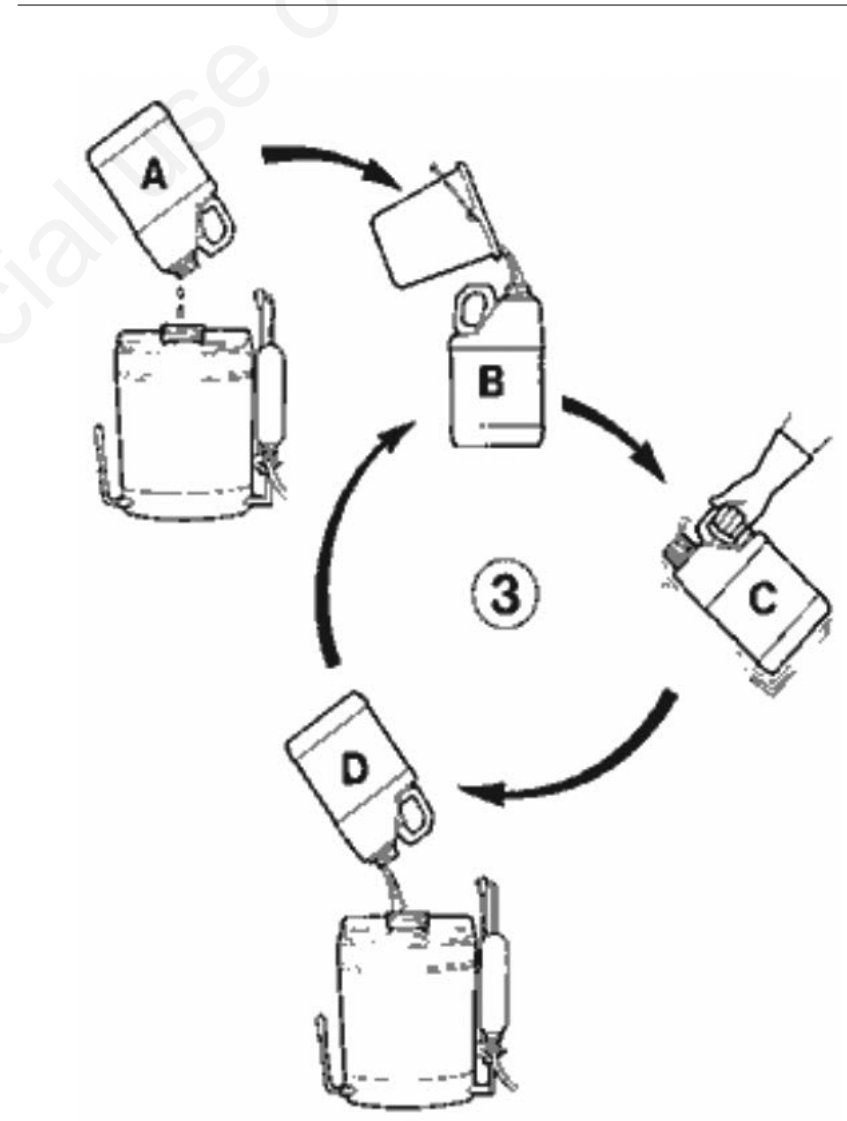

Figure 2. Triple-rinsing procedure, according with the AgroChePack project. A) Drain the container from the remaining pesticide for at least $30 \mathrm{~s}$ into the sprayer tank. B) Add clean water to the empty container $25-30 \%$ of its capacity. C) Replace cap firmly and shake for at least $30 \mathrm{~s}$, making sure that all the inner surfaces of the container are well rinsed. Large containers may need to be rotated or rolled. D) Remove the cap and empty the rinsing into the sprayer tank, so that it forms part of the spray mix. Allow it to drain for at least $30 \mathrm{~s}$. E) Repeat steps A-D twice more. If the rinse water is still colored or milky after three rinses, then repeat the rinsing process until the rinse water is clear. 
contained the herbicide Axial ${ }^{\circledR}$ Pronto 60 by Syngenta having the following active ingredients: $60 \mathrm{~g} / \mathrm{L}$ pinoxaden, $15 \mathrm{~g} / \mathrm{L}$ cloquintocet-mexyl and other co-formulants with reported limited hazardousness. One of the two bottles was filled for one third of its volume and, prior to decontamination, it was subject to artificial accelerated weathering in order to simulate thermo-oxidative degradation (Gulmine et al., 2003; Pfennig et al., 2016).

The aging was performed in two steps: firstly, the herbicide container was heat-treated under an oven temperature of $55^{\circ} \mathrm{C}$ for $96 \mathrm{~h}$. Then, the same was transferred for $16 \mathrm{~h}$ into a UV irradiation box equipped with 13 multi-directional LEDs with a power of 39 $\mathrm{W}$ each, under a $400 \mathrm{~nm}$ wavelength and a temperature of $55^{\circ} \mathrm{C}$. Afterwards, both bottles were completely emptied and triplerinsed as specified in the Guidelines with deionised water. A fourth washing was necessary because of insufficient clarity of the cleansing water.

\section{Extraction of pesticides}

Possible absorption of agrochemicals in the plastic matrix of the containers was investigated by extracting the remaining pesticide using a mixture of solvents. Although a standardised extraction procedure is not yet in place, several authors have tried to find common grounds for the extraction of different types of pesticide from containers of different polymeric blends (Briassoulis et al., 2014; Eras et al., 2017). For this work, the procedure described by Eras et al. (2017) was applied, with some changes related to the specific nature of the pesticide and to the particular purpose of this work.

The aged bottle was cut at the level of the pesticide prior emptying: this served with the purpose of evaluating the different superficial degradation of the polymer aged in contact with the pesticide (simulating the long-time storage of not fully used pesticides) and not in contact with the pesticide (simulating the longtime storage of an empty container without immediate decontamination). These two parts, as well as the not-aged bottles, were cut in two halves each for replicates. Each half was cut into $1 \times 1 \mathrm{~cm}$ pieces and of these, few samples were kept for surface degradation analysis. The solvent used for extraction was a 50:50 mixture of acetone and methanol and $135 \mathrm{~mL}$ of this solvent mixture were poured in the bottles containing the polymer samples. In order to accelerate the extraction, the glass bottles were placed on a HS501 digital shaker by IKA (Germany) at a rotation speed of $560 \mathrm{rpm}$ for one hour. Afterwards the extraction solvent was stored for further analysis on the concentration of pesticide in the solution and the extraction procedure was once more performed with $135 \mathrm{ml}$ fresh solvent mixture, placing the bottles in the shaker and storing the extraction solution.

\section{Characterisation}

The samples were analysed by means of liquid chromatography-tandem mass spectrometry (LC-MS/MS), used to analyse the active ingredients' concentration in water and in the solvent mixture after the extraction steps.

Environmental hazards associated with ineffective APPW triple-rinsing decontamination were assessed through the determination of the $\mathrm{LC}_{50}$ factors - defined as the concentration of a chemical in air or in water causing the death of $50 \%$ of a group of test animals - of the mixtures, as regulated in the Regulation $\mathrm{n}$. $1272 / 2008$ of the European Parliament and of the Council on classification, labelling and packaging of substances and mixtures listing the classification criteria and the hazard communication elements by type of hazard (European Parliament, 2008).

Scanning electron microscopy was used to characterise sur- face's alterations of the polymer after accelerated ageing conditions, as well as to assess the influence of container's ageing in contact with the pesticide. The samples' surface was coated with a $15 \mathrm{~nm}$ layer of gold by sputtering using a Sputter Coater SCD 050 by BalTec (Pfäffikon, Switzerland), and then they were inserted in a Leo Gemini 1530 by Zeiss (Oberkochen, Germany) with a voltage of $15 \mathrm{kV}$ for analysis. Photomicrographs were taken with a magnification of $100 \mathrm{X}$ and $1000 \mathrm{X}$.

\section{Results and discussion}

Overall, the analysis conducted in the framework of the AgroChePack project have shown that, considering the present legal limits established for pesticides, the recycling of the polymeric packages that have contained pesticides is anyway feasible after a triple-rinsing procedure. The hazardousness analysis of the triple-rinsed containers collected from the pilot trials confirmed the laboratory experiments results, suggesting that the appropriate application of the triple-rinsing technique of the containers by suitably trained farmers ensures their decontamination and their characterisation as non-hazardous waste according to the European Waste Catalogue (EWC) provisions. The triple-rinsing of empty bottles removes most of the pesticides, achieving levels below legal limit; this removal has been demonstrated for all cases with one exception. However, for some pesticide/polymer combinations, the significant amount of pesticide that persists within the polymer could be later released during recycling or reuse. Depending on the future use of these polymers, besides being legally feasible, the product obtained after the recycling process has not to introduce risks (Briassoulis et al., 2014).

\section{Decontamination procedure}

According to the composition of the pesticide, the concentration thresholds for its hazardousness were evaluated on the basis of the Regulation n. 1272/2008 (European Parliament, 2008). The acute (short-term) toxicity in aquatic environment was evaluated for both mixtures of the not aged and of the aged APPW. The mixture contained in the not aged APPW had a $\mathrm{LC}_{50}$ value of 9.83 $\mathrm{mg} / \mathrm{L}$ and that in the aged APPW had a $\mathrm{LC}_{50}$ value of $10.04 \mathrm{mg} / \mathrm{L}$. According to the limits identified in the Regulation, no classification for acute toxicity was needed.

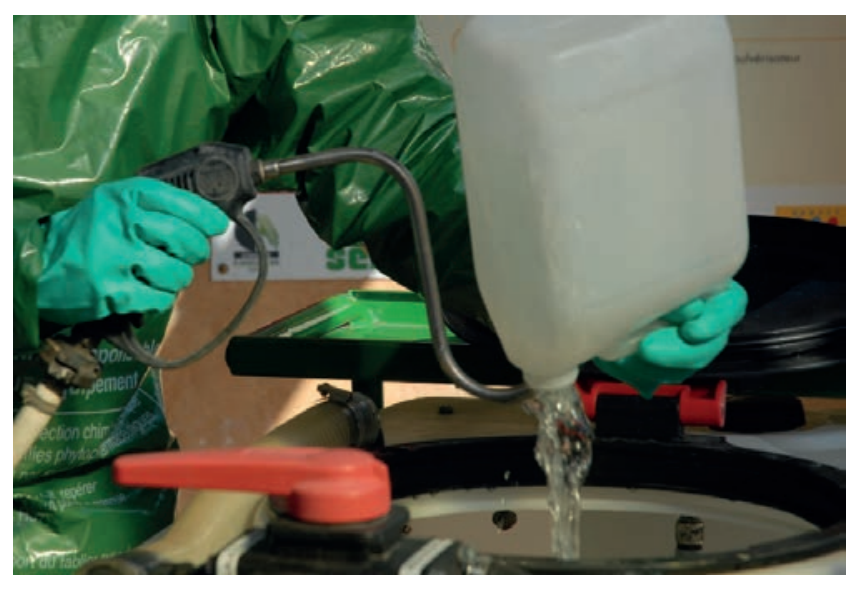

Figure 3. Triple-rinsing at the AgroChePack pilot station in Cellamare (BA, Italy). 
In this case, the triple-rinsing decontamination procedure was effective enough to classify the APPW as non-hazardous waste. However, although the investigated active ingredients do not have documented risks for health, significant consequences can be expected in the mechanical recycling phase, in which water is used for both steps of washing and density separation. As a consequence, subsequent possible contaminants might be expected to be transferred to the processing water and, potentially, to the recycled.

\section{Inner surface structure}

The effect of ageing is evident already from a low magnification (Figure 4): the inner surface of the polymer shows an increased roughness in case the container is aged in contact with the pesticide (Figure 4C). In addition to this, a higher magnification (1000X as shown in Figure 5) reveals a degradation pattern that differs whether the container is: A) not aged; B) aged not in contact with the pesticide; and C) aged in contact with the pesticide. Specifically, after ageing small hollows in the surface of the polymer occur, independently from the contact with the pesticide. However, aging the polymer in contact with the pesticide, not only produces the above-mentioned hollows and increased roughness, but it also causes pesticide contaminants to crystallise.

This degradation pattern mainly affects the effectiveness of the decontamination procedure. As a matter of fact, increased roughness and a consequent crystallisation of the pesticide contaminant onto the polymeric surface are likely to hinder the triple-rinsing efficacy. As a final outcome, if the container is treated as non-haz- ardous and so delivered to a plastic recycling facility, it may possibly cause contamination of the recycled.

\section{Conclusions}

From the results that were obtained by the pilot tests at Project level, it could be concluded that all containers rinsed at the AgroChePack pilot station under supervision were decontaminated according to the limits for non-hazardous waste set by the legislation, while those triple-rinsed by farmers on their own responsibility (i.e., outside the pilot station) were only partially decontaminated. One of the most evident limits of the triple-rinsing method has revealed indeed that farmers in some cases do not appropriately triple-rinse the containers or, mainly, they do not triple-rinse them immediately after the use of the agrochemical.

Triple-rinsing a plastic container much time after its emptying, or that has been partially used and which has remained too much time half-used, results in fact into the formation of hollows and into an increase of roughness of the polymer surface, as well as into the crystallisation on the empty internal side of the plastic container of chemical elements which are not removed, even through an appropriate triple-rinsing procedure. Although this does not pose direct risks to the environment, it can represent a hindrance to the recycling process of the APPW and, consequently, to the material's circularity.

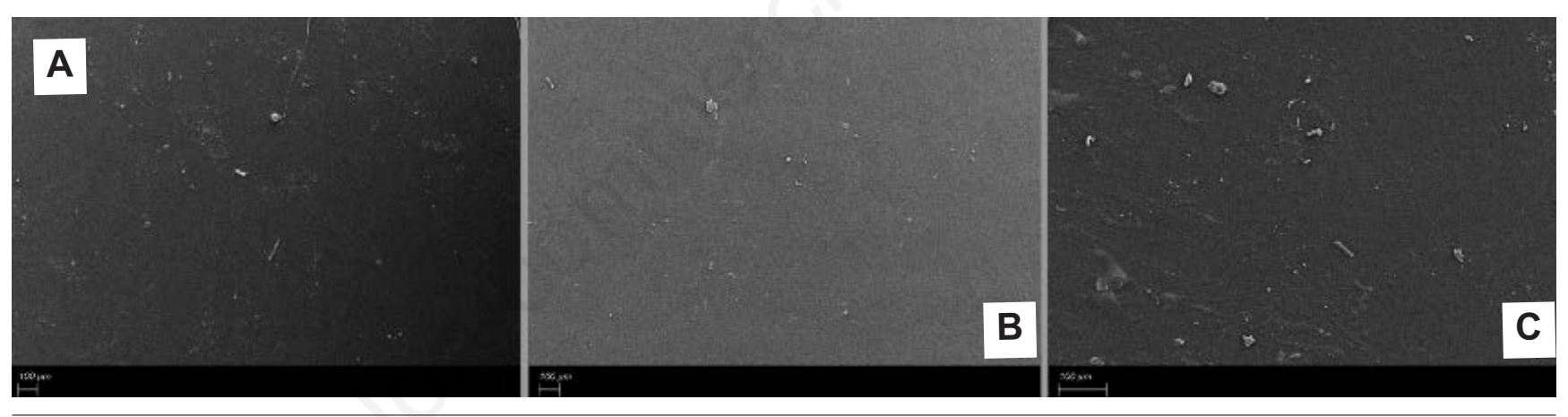

Figure 4. Scanning electron microscopy micrographs at $100 \mathrm{X}$ magnification. A) Not-aged sample; B) sample aged not in contact with pesticide; C) sample aged in contact with pesticide.
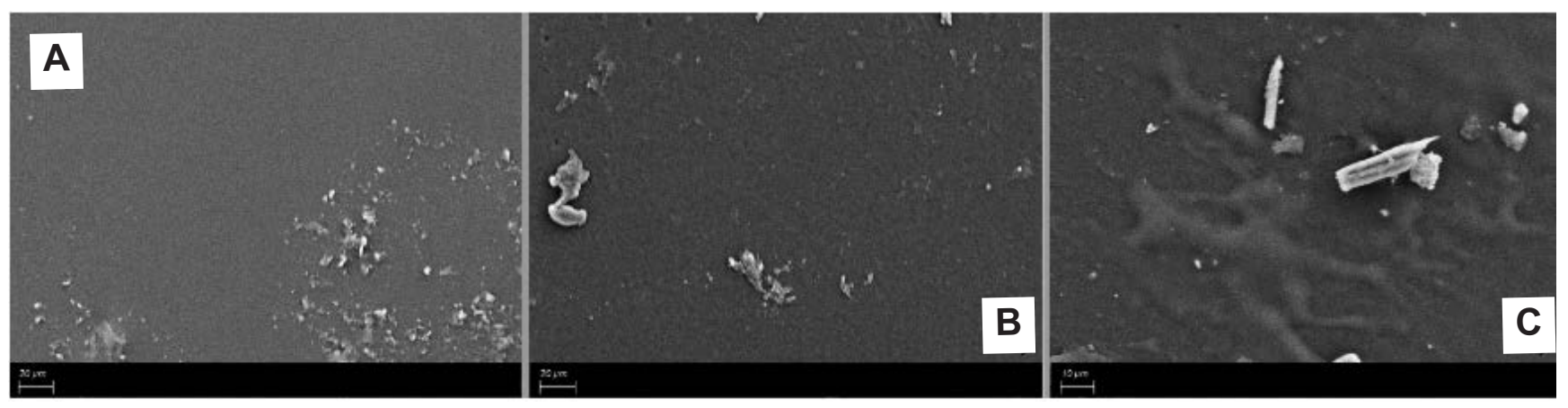

Figure 5. Scanning electron microscopy micrographs at 1000X magnification. A) Not-aged sample; B) sample aged not in contact with pesticide; C) sample aged in contact with pesticide. 


\section{References}

AgroChePack Project. 2013. Design of a common agrochemical plastic packaging waste management scheme to protect natural resources in synergy with agricultural plastic waste valorisation. Programme Interreg MED, Contract No. 2G-MED09-15, 2010-2013. Available from: http:/www.agrochepack.aua.gr/ Accessed: 4 May 2019.

Alassali A, Moon H, Picuno C, Meyer RSA, Kuchta K, 2018. Assessment of polyethylene degradation after aging through anaerobic digestion and composting. Polym. Degrad. Stabil. 158:14-25.

Ben Salem A, Chaabane H, Lahbib N, Salghi R, Fattouch S, 2019. Management of phytosanitary effluent: Rinsing and decontamination of empty pesticide containers by bio-detergent. Crop Prot. 116:142-55.

Blanco I, Loisi RV, Sica C, Schettini E, Vox G, 2018. Agricultural plastic waste mapping using GIS. A case study in Italy. Resour. Conserv. Recycl. 137:229-42.

Briassoulis D, Babou E, Hiskakis M, Scarascia-Mugnozza G, Picuno P, Guarde D, Dejean C, 2013. Review, Mapping and analysis of the agricultural plastic waste generation and consolidation in Europe. Waste Manage. Res. 31:1262-78.

Briassoulis D, Hiskakis M, Babou E, Antiohos SK, Papadi C, 2012. Experimental investigation of the quality characteristics of agricultural plastic wastes regarding their recycling and energy recovery potential. Waste Manage. 32:1075-90.

Briassoulis D, Hiskakis M, Karasali H, Briassoulis C, 2014. Design of a European agrochemical plastic packaging waste management scheme - Pilot implementation in Greece. Resour. Conserv. Recycl. 87:72-88.

Briassoulis D, Hiskakis M, Scarascia Mugnozza G, Picuno P, Delgado C, Dejean C, 2010. Labelling scheme for agricultural plastic wastes in Europe. Qual. Assur. Saf. Crop. 2:93-104.

D. Lgs. N.22/1997. Decreto Legislativo 5 febbraio 1997 No 22 Attuazione delle direttive 91/156/CEE sui rifiuti, 91/689/CEE sui rifiuti pericolosi e 94/62/CE sugli imballaggi e sui rifiuti di imballaggio (Implementation of waste directives 91/156/EEC, 91/689/EEC on hazardous waste and 94/62/EC on packaging and packaging waste).

D. Lgs. N.152/2006. Decreto Legislativo 3 aprile 2006 No 152 Allegato D: Norme in materia ambientale (Annex D: Environmental rules).

Damalas CA, Teilidis GK, Thanos SD, 2008. Assessing farmers' practices on disposal of pesticide waste after use. Sci. Total Environ. 390:341-5.
Dimitrijevic A, Sica C, Picuno P, Scarascia-Mugnozza, G, 2013. Using the glass fibres in recycling agricultural plastic waste. Poljoprivredna Tehn. (Agric. Engine. Sci. J.) 38:31-8.

Eras J, Costa J, Vilarò F, Pelacho AM, Canela-Garayoa R, MartinClosas L, 2017. Prevalence of pesticides in postconsumer agrochemical polymeric packaging. Sci. Total Environ. 580:1530-8.

European Parliament and Council, 2008. Classification, labelling and packaging of substances and mixtures, amending and repealing Directives 67/548/EEC and 1999/45/EC, and amending Regulation (EC) No 1907/2006. In: Official Journal, L 353, 31.12.2008, pp 130-139.

Gulmine JV, Janissek PR, Heise HM, Akcelrud L, 2003. Degradation profile of polyethylene after artificial accelerated weathering. Polym. Degrad. Stabil. 79:385-97.

Labelagriwaste Project. Labelling Agricultural Plastic Waste for Valorising the Waste Stream. Programme FP6 RTD CRAFTCollective Research, 2006-2009. Contract No. 516256-2. Available from: https://labelagriwaste.aua.gr:8443/law/ Welcome.do

Lanorte A, De Santis F, Nolè G, Blanco I, Loisi RV, Schettini E, Vox G, 2017. Agricultural plastic waste spatial estimation by Landsat 8 satellite images. Comput. Electron. Agr. 141:35-45.

Picuno P, 2014. Innovative material and improved technical design for a sustainable exploitation of agricultural plastic film. Polym-Plast. Technol. 53:1000-11.

Picuno P, Scarascia-Mugnozza G, Sica C, Dimitrijevic A, Laviano R, 2012. Experimental tests and technical characteristics of regenerated films from agricultural plastics. Polym. Degrad. Stabil. 97:1654-61.

Pfennig L, Kuchta K, Prette A, Fiore S, 2016. Evaluation of LDPE and ABS degradation by means of NIR spectroscopy. Proc. 5th International Conference on Industrial \& Hazardous Waste Management, Crete, Greece.

Scarascia-Mugnozza G, Sica C, Picuno P, 2008. The optimization of the management of agricultural plastic waste in Italy using a geographical information system. Acta Hortic. 801:219-26.

Sica C, Godosi Z, Picuno P, 2013. The management of agricultural plastic packaging waste: a pilot experimentation in southern Italy. Proc. ISAE-2013 - The First International Symposium on Agricultural Engineering. Belgrade-Zemun, pp. 69-76.

Vox G, Loisi RV, Blanco I, Scarascia-Mugnozza G, Schettini E, 2016. Mapping of agriculture plastic waste. Agric. Agric. Sci. Proc. 8:583-91. 